\title{
An innovative technique for osteoporotic vertebral compression fractures - vertebral osteotome with side-opening cannula
}

This article was published in the following Dove Press journal: Journal of Pain Research

\author{
Xin $\mathrm{He}^{1}$ \\ Yang Liu ${ }^{2}$ \\ JiaNan Zhang' \\ ShuaiJun Jia' \\ YiBin Meng' \\ YunFei Huang' \\ QiNing $\mathrm{Wu}^{\prime}$ \\ DingJun $\mathrm{HaO}^{\prime}$ \\ 'Department of Spine Surgery, Hong \\ Hui Hospital, Xi'an Jiaotong University \\ Health Science Center, Xi'an 710054, \\ Shaan'xi Province, China; ${ }^{2}$ Department \\ of Bone Microsurgery, Hong Hui \\ Hospital, Xi'an Jiaotong University \\ Health Science Center, Xi'an 7I0054, \\ Shaan'xi Province, China
}

Correspondence: DingJun Hao Department of Spine Surgery, Hong Hui Hospital, Xi'an Jiaotong University Health Science Center, No. 76, Nanguo Road, Nanshao Gate, Xi'an 7I0054, Shaan'xi Province, China

Tel +86 I390929 7839

Fax +862987894724

Email haodjspine@126.com
Objective: This study is to assess an innovative technique - a vertebral osteotome (VO) combined with side-opening injection cannula for percutaneous vertebroplasty (PVP).

Methods: A retrospective study by propensity score matching. From January 2016 to April 2016, 63 patients who were diagnosed with monosegmental osteoporotic vertebral compression fracture received the innovative technique. The epidemiologic data, surgical indexes, and recovery outcomes were collected in the follow-up period. Propensity score matching identified 63 pairs form historical controls by traditional unilateral PVP approach in 2015 using six independent variables: age, sex, preoperative visual analog score (VAS), Oswestry Disability Index (ODI), body mass index, and bone mineral density.

Results: The surgical duration and cement distribution were longer and larger in patients by VO method. Besides, postoperative VAS and ODI in the VO group were lower than those in the control group. However, there were no differences in radiation exposure times, improvement of Cobb angle, cement leakage, or adjacent vertebral fracture between two groups. Cement volume in the VO group was less than that in the control group.

Conclusion: This new innovative technique makes PVP safe and effective. Although it lasts longer, the restoration rate of vertebral height and cement distribution can be improved, which contributes to a better pain relief.

Keywords: technique, percutaneous vertebroplasty, vertebral osteotome, osteoporotic vertebral compression fracture, side-opening injection cannula

\section{Introduction}

Osteoporotic vertebral compression fracture (OVCF) was a menace to the elderly generation, which caused diminished quality of life due to pain and deformity. ${ }^{1}$ More than $25 \%$ of women aged 50 years and older will have one or more vertebral compression fractures by $2025 .^{2}$ Percutaneous vertebroplasty (PVP) was a minimally invasive surgical procedure for the management of $\mathrm{OVCF}^{3}$ It also provided rapid pain relief and stabilization of the fractured vertebral bodies. ${ }^{4}$ PVP was necessary after the failure of 2-3 weeks of conservative treatment including pain medication and physiotherapy, which had gained popularity as a new treatment of OVCF. ${ }^{5}$

PVP was one of the optimal treatments for OVCF, but the matter of surgical approach selection remained controversial. Traditional bilateral PVP was shown to be safe and effective for OVCF ${ }^{6,7}$ Nevertheless, it showed increased surgery time and injected cement volume, and the risk of bone cement leakage was twice that of the unilateral approach. ${ }^{8}$ The unilateral PVP would be an attractive alternative to the traditional 
bilateral PVP owing to theoretical speed, safety, and lower X-ray irradiation. ${ }^{9}$ Meanwhile, asymmetric distribution of bone cement leading to spinal instability in the vertebral body by using unilateral technique had been reported in a research. ${ }^{10}$ For achieving the advantages of both unilateral and bilateral approach, we developed an innovative technique proceeding PVP and compared it with a traditional method.

\section{Methods}

\section{Patients}

Between January 2016 and April 2016, patients who were diagnosed as monosegmental OVCF were recruited in our study. The inclusion criteria were as follows: 1) tenderness or percussion pain at fractured vertebral body surface in the recent 1 year; 2) vertebrae fracture without any pressure in spinal canal or nerve lesion by X-rays; 3 ) osteoporosis (diagnosed by bone mineral density [BMD], calculated as T value $\leq-2.5)$; 4) intact vertebral posterior wall; 5) new fractures without any other fractures in vertebrae.

The excluding criteria were as follows: 1) patients lost to follow-up; 2) a patient history of previous PVP or percutaneous kyphoplasty; 3) clinical or imaging evidence of metastatic bone tumor or multiple myeloma; 4) complications in endocrine system (such as diabetes, thyroid dysfunction, and so on).

Each patient took physical examinations and spinal radiographs on the day before surgery and 3 months after surgery. The study protocol was approved by the ethics committee of Hong Hui Hospital, Xi' an Jiaotong University, and informed consent was obtained from all patients.

We confirmed that all methods were carried out in accordance with relevant guidelines and regulations of our licensing committee. We confirmed that all experimental protocols were approved by licensing committee of Xi'an HongHui Hospital, and all patients were informed and provided written informed consent. The informed consent for publication of identifying images has been approved by the relevant patient.

\section{Devices composition}

A series of novel devices were invented for the application of unilateral PVP in the present study. The most important part was vertebral osteotome (VO; Figure 1A). The ending of $\mathrm{VO}$ could bend from $0^{\circ}$ to $90^{\circ}$, which was helpful to make a curved cavity in the vertebral body. Surgeons could rotate the handle knob at the bottom of the VO to control the bending degrees. It could work better with side-opening injection cannula (Figure 1B). Compared to the traditional ones, there was an opening on the side of our cannula. So, the device had the ability of directional bone cement delivery. The handspike was the instrument that can go through the cannula, which could promote the movement of bone cement in the cannula. Then the bone cement could be injected into vertebral body through the side-opening injection cannula by the cement handspike (Figure 1C). Now the VO and its accessorial devices are commercially used in the hospital.

\section{Surgical procedures}

The surgery was performed under general anesthesia and unilateral approach. X-ray fluoroscopy was used throughout the whole procedure. A skin incision was made on the pedicle level of the fractured vertebral body. Then the needle and pin were placed via the stab incision. The pin was not removed until it reached $2-3 \mathrm{~mm}$ depth of posterior vertebral body wall. Next, a wire pin was fixed into the vertebral body. The needle pipe was removed and a working cannula was constructed. Subsequently, the VO was inserted through the cannula after the wire pin was withdrawn. By using its flexible end, VO could make a curved cavity in the fractured vertebral body. The resulting cavity was filled with polymethylmethacrylate (PMMA) cement, which was injected by cement handspike through the side-opening injection cannula (Figure 2).

\section{Research indexes}

Research indexes included three parts: surgery outcomes, clinical assessment, and radiographic outcomes. All preoperative and postoperative data were recorded on the day before surgery and 3 months after surgery.

Surgery outcomes: The cement volume, surgical duration, and radiation exposure times were recorded by the operators during the surgery process.

Clinical assessment: It was evaluated using the Oswestry Disability Index (ODI) and the visual analog scale. Both preoperative and postoperative ODI and visual analog score (VAS) were recorded.

Radiographic outcomes: BMD was measured by X-ray radiographic absorptiometry. The restoration rate of vertebral height was calculated as (postoperative vertebral height preoperative vertebral height)/(predicted primary vertebral height - preoperative vertebral height)*100\%. The predicted primary vertebral height was the mean height of two vertebrae adjacent to the injured vertebra. The improvement of Cobb angle was calculated as follows: (preoperative Cobb angle - postoperative Cobb angle). Cobb angle was measured from the superior endplate of vertebra one level above the fractured vertebra to the inferior endplate of the vertebral 


\section{A}
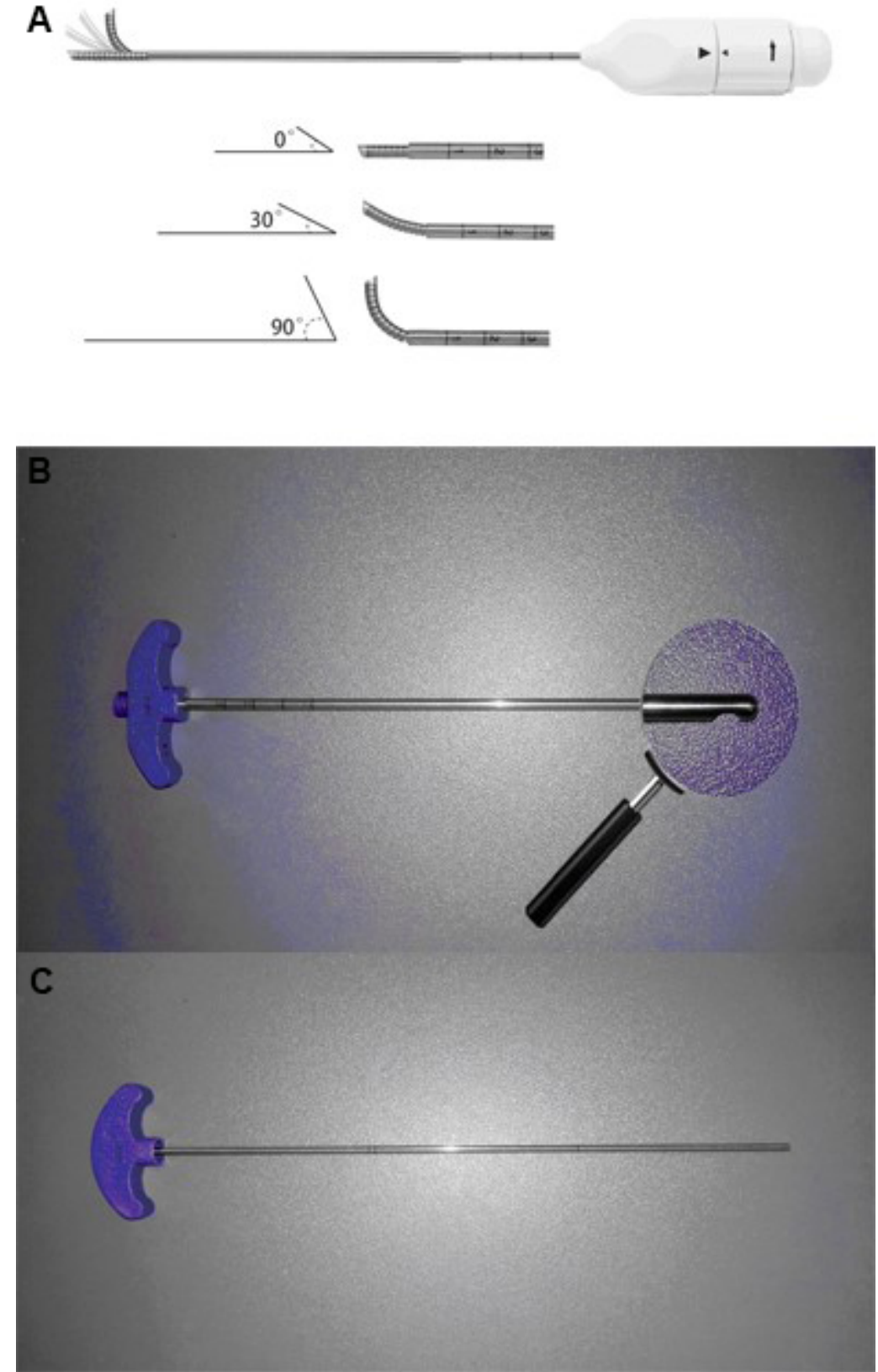

Figure I The physical diagram of novel devices in our study.

Note: The new instruments include vertebral osteotome (A), side-opening bone filler device (B), and bone cement handspike (C).

one level below the fractured vertebra on the lateral X-ray image. The cement distribution was calculated as the mean ratio of bright areas to the whole fractured vertebra area both in the anteroposterior (AP) and lateral views under X-rays during the surgery (Figure 3). Cement leakage was defined as any presence of extravertebral high cement signal observed by X-ray. Adjacent vertebral fracture postoperatively was defined with any vertebral fracture next to the treated vertebral body.

\section{Statistical analysis}

Propensity Score Matching (PSM) was used in our analysis. Propensity matched pairs were identified by matching on the following six independent variables: age, sex, preoperative VAS, preoperative ODI, BMI, and BMD. Propensity matching of subjects was performed by the method of nearest distance with a 1:1 ratio (Figure 4). Data were analyzed using the SAS9.1 software (SAS Institute Inc, Cary, NC, USA). Numeric variables were expressed as mean \pm SD. Nominal 


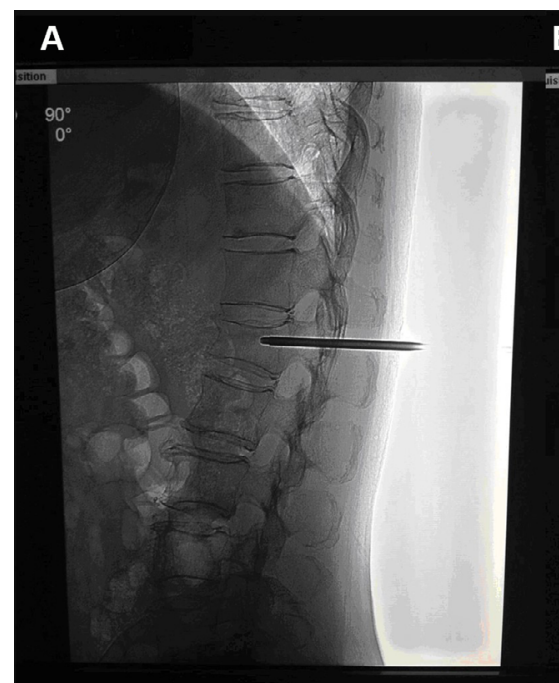

B

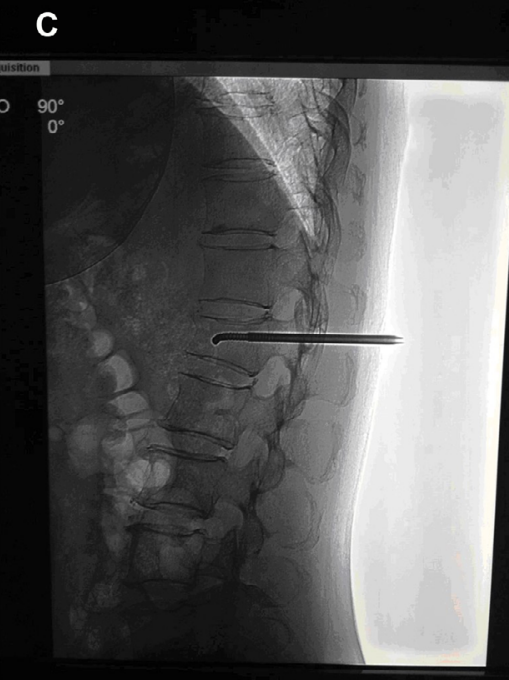

D

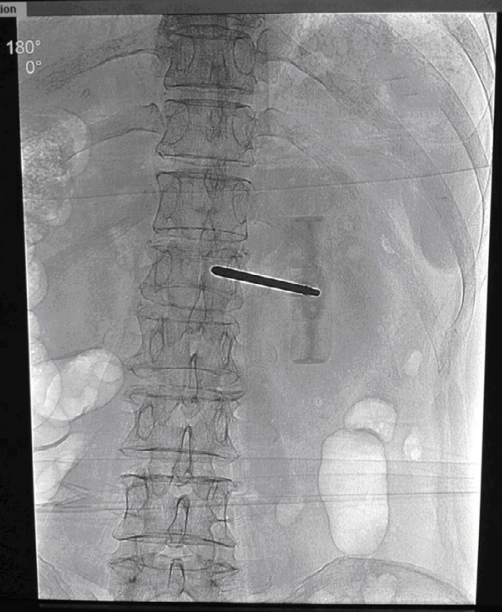

D

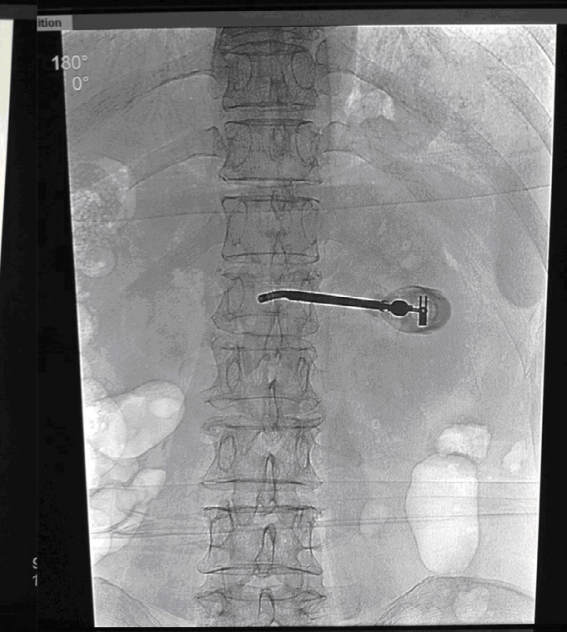

$\mathbf{E}$

$\mathbf{F}$

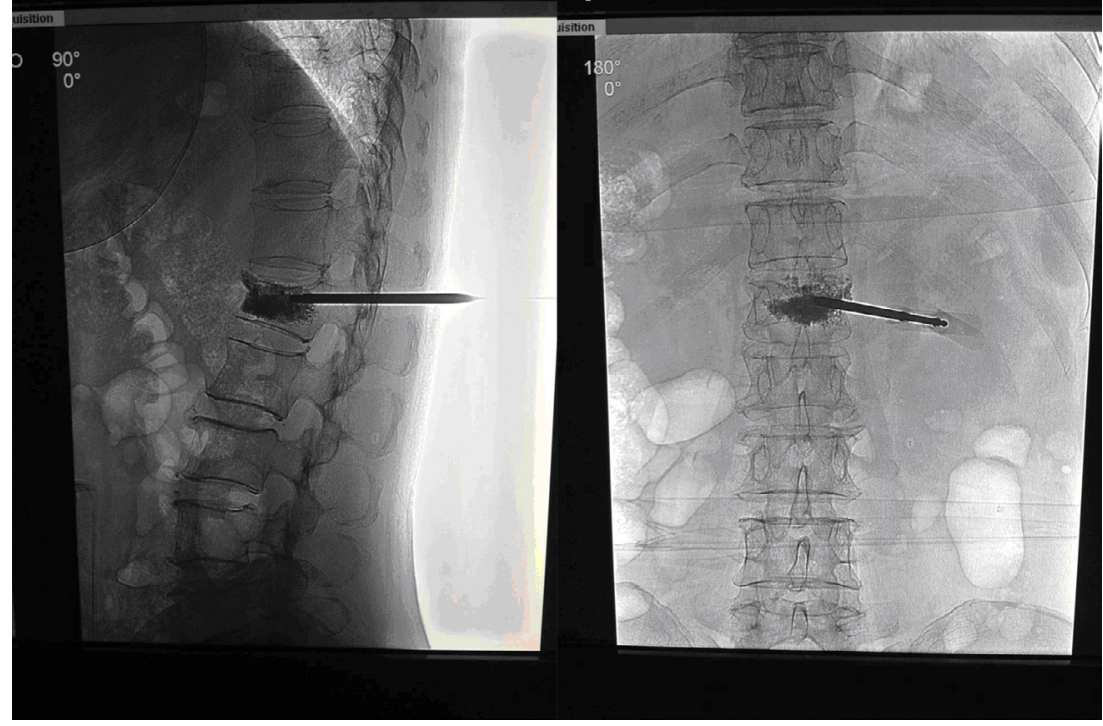

Figure 2 The actual operation chart of $\mathrm{VO}$ with side-opening bone filler device in surgical procedures.

Notes: VO was inserted through cannula both in the lateral (A) and anteroposterior view (B). VO bent to $90^{\circ}$ in the fractured vertebral body both in the lateral (C) and anteroposterior view (D). Cement was injected through the side-opening bone filler device both in the lateral $(\mathbf{E})$ and anteroposterior view $(\mathbf{F})$.

Abbreviation: $\mathrm{VO}$, vertebral osteotome. 


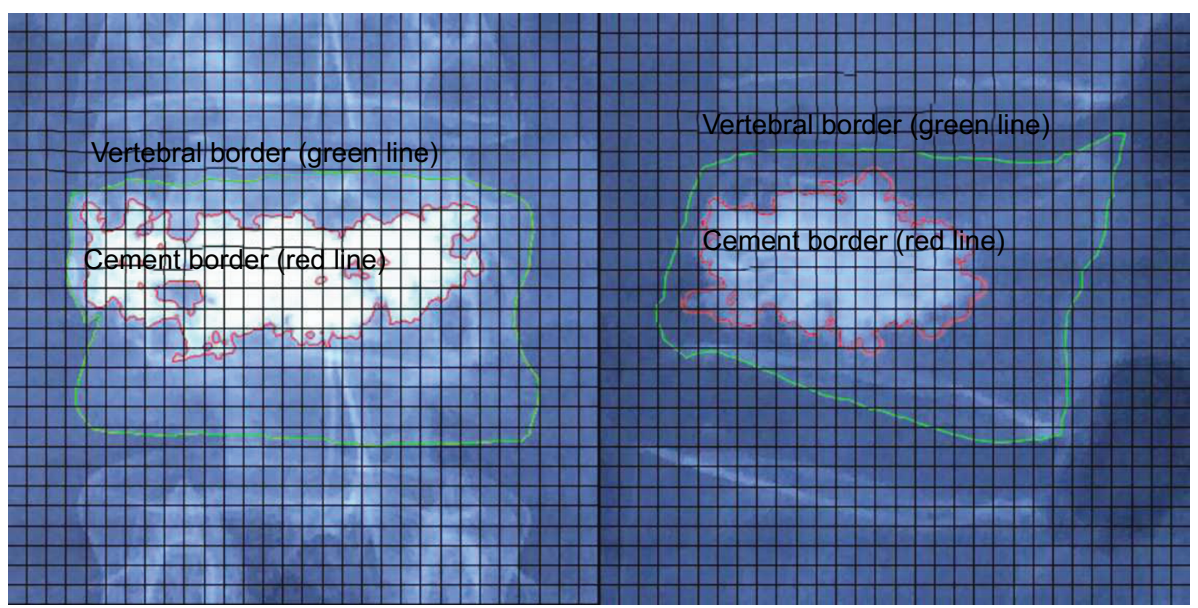

Figure 3 Measurement of cement distribution.

Notes: We selected the portion of fractured vertebra in the picture and put it into a new $15^{*} 15 \mathrm{~cm}$ transparent layer. The layer was divided by a number of the same sized squares. The area of each square was $0.25 \mathrm{~mm}^{2}$. Different brightness areas were selected by the software automatically. The green line meant vertebral border and the red line meant cement border. If the selected area was more than half the whole square, the area was calculated as 1 . Otherwise, it was 0 . Then the ratio of cement area to vertebral cross-sectional area was estimated. From the picture we can see that the cement distributions were 105/307 and 88/269 in the anteroposterior and lateral views, respectively. So the total cement distribution was $66.92 \%$.

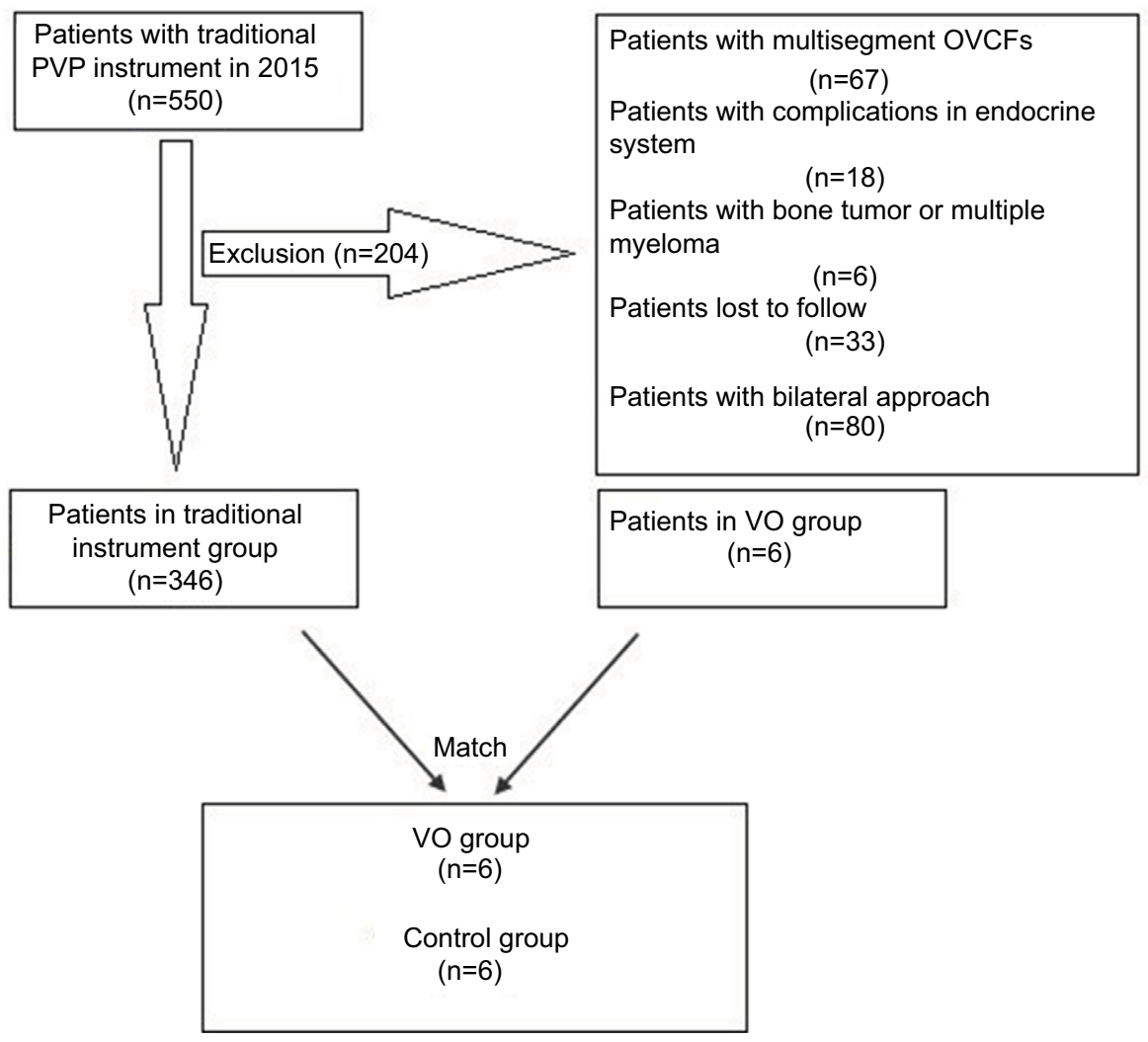

Figure 4 Flow diagram of study.

Abbreviations: OVCFs, osteoporotic vertebral compression fractures; PVP, percutaneous vertebroplasty; VO, vertebral osteotome.

variables were expressed as numbers (percentage). The chisquared test was used for the univariate analyses of categorical data and the independent $t$-test was used for the univariate analyses of continuous data between the VO group and the control group. The statistical significance was set at $P<0.05$.

\section{Results}

\section{General information}

A total of 20 men and 43 women with 45 lumber vertebras and 18 thoracic vertebras underwent PVP by VO in our hospital. The mean age of patients was $59.4 \pm 10.0$ years 
(45-86 years). BMI and BMD were $22.83 \pm 3.16 \mathrm{~kg} / \mathrm{m}^{2}$ and $-3.6 \pm 0.7$, respectively. After surgery, the VAS decreased from $7.2 \pm 1.8$ to $2.9 \pm 1.5(t=13.855, P<0.001)$, which indicated an obvious pain relief. The ODI also improved from $54.3 \pm 5.1$ to $12.4 \pm 1.7(t=60.499, P<0.001)$.

To compare the VO method with the traditional technique method in proceeding surgery, we identified data from records of 550 patients with OVCF who underwent PVP in 2015. Of all 550 patients, 80 patients received a bilateral surgical approach, 67 patients had multisegment OVCFs, 33 patients were lost to follow-up, 18 patients had endocrine system diseases, and six patients were diagnosed with bone tumor and multiple myeloma. There were only 346 patients left in the historical controls. After stratifying and matching, 63 patients in the VO group were paired with 63 patients in the control group. Moreover, there were no statistically significant differences in age, sex, BMI, BMD, preoperative VAS, or ODI between two groups (Table 1).

\section{Surgery outcomes comparison}

The surgical duration and cement distribution in the VO group were $27.7 \pm 5.4$ minutes and $0.64 \pm 0.20$, respectively. They were both larger than that in the control group $(t=4.391$, $P<0.001 ; t=7.860, P<0.001)$. Cement volume in the VO group was less than that in the control group $(3.5 \pm 0.8$ vs $4.0 \pm 1.0$, $t=-2.890, P=0.005)$. However, the total time of fluoroscopic radiation exposure in the VO group was $13.4 \pm 3.7$, which showed no differences with that in the control group (Table 2).

\section{Clinical assessment and radiographic outcomes comparison}

VAS was decreased obviously at 3 months after surgery in each group, whereas postoperative VAS in the VO group was significantly lower than that in the control group $(2.9 \pm 1.5$ vs $4.2 \pm 1.5, t=-4.823, P<0.001)$. The postoperative ODI in

Table I The comparison of baseline characteristics between two groups

\begin{tabular}{llll}
\hline Characteristics & $\begin{array}{l}\text { VO group } \\
(\mathbf{n}=63)\end{array}$ & $\begin{array}{l}\text { Control } \\
\text { group } \\
(\mathbf{n}=63)\end{array}$ & P-value \\
\hline Sex (male) & $20(31.7 \%)$ & $29(46.0 \%)$ & 0.100 \\
Age (years) & $59.4 \pm 10.0$ & $59.2 \pm 5.1$ & 0.877 \\
BMI (kg/m $\left.{ }^{2}\right)$ & $22.83 \pm 3.16$ & $22.96 \pm 3.12$ & 0.818 \\
BMD (T value) & $-3.6 \pm 0.7$ & $-3.4 \pm 0.6$ & 0.274 \\
Preoperative VAS & $7.2 \pm 1.8$ & $7.2 \pm 1.9$ & 0.931 \\
Preoperative ODI & $54.3 \pm 5.1$ & $53.2 \pm 4.5$ & 0.196 \\
\hline
\end{tabular}

Abbreviations: BMD, bone mineral density; BMI, body mass index; ODI, Oswestry Disability Index; VAS, visual analog score; VO, vertebral osteotome. the VO group was also better than that in the control group $(12.4 \pm 1.7$ vs $19.0 \pm 1.9, t=-20.534, P<0.001)$. Besides, the restoration rate of vertebral height in the VO group was higher than that in the control group (45.79 \pm 9.46 vs $30.23 \pm 16.43$, $t=6.513, P<0.001)$. The improvement of Cobb angle was $4.08 \pm 1.10^{\circ}$ in the VO group, which showed no statistically differences with that in the control group.

A total of two patients experienced cement leakage in the follow-up period. The site of leakage was intervertebral disc, but no one had clinical manifestations. Only one patient had an adjacent vertebral fracture in L3 level. The pain disappeared after reoperation. There were no differences in complications between VO group and the control group (Table 3).

\section{Discussion}

Effects of PVP in treating OVCFs have been demonstrated in many studies. ${ }^{11-13}$ It brings the pain relief and normal activities to patients with OVCF. At the same time, problems such as asymmetric distribution of bone cement, refractures after operation, and vertebrae recollapse also exist in traditional PVP method ${ }^{14}$. The principal goal of surgery for treating OVCF is to restore the height of fractured vertebral body and to reduce its kyphosis deformity. ${ }^{15}$ Therefore, the restoration rate of vertebral height was used as radiographic outcomes

Table 2 The comparison of surgery outcomes between two groups

\begin{tabular}{llll}
\hline Surgery indexes & $\begin{array}{l}\text { Vertebral } \\
\text { osteotome } \\
\text { group } \\
(\mathbf{n}=63)\end{array}$ & $\begin{array}{l}\text { Control } \\
\text { group } \\
(\mathbf{n}=63)\end{array}$ & P-value \\
\hline Surgical duration (minutes) & $27.7 \pm 5.4$ & $24.2 \pm 3.2$ & $<0.00 \mathrm{I}$ \\
Cement volume $(\mathrm{mL})$ & $3.5 \pm 0.8$ & $4.0 \pm 1.0$ & 0.005 \\
Radiation exposure times $(\mathrm{s})$ & $13.4 \pm 3.7$ & $12.6 \pm 4.2$ & 0.249 \\
Cement distribution $(\%)$ & $0.64 \pm 0.20$ & $0.42 \pm 0.10$ & $<0.00 \mathrm{I}$ \\
\hline
\end{tabular}

Table 3 The comparison of clinical assessment and radiographic outcomes between two groups

\begin{tabular}{|c|c|c|c|}
\hline $\begin{array}{l}\text { Clinical assessment and } \\
\text { radiographic outcomes }\end{array}$ & $\begin{array}{l}\text { VO group } \\
(n=63)\end{array}$ & $\begin{array}{l}\text { Control } \\
\text { group } \\
(n=63)\end{array}$ & $P$-value \\
\hline Postoperative VAS & $2.9 \pm 1.5$ & $4.2 \pm 1.5$ & $<0.001$ \\
\hline Postoperative ODI & $12.4 \pm 1.7$ & $19.0 \pm 1.9$ & $<0.001$ \\
\hline Improvement of Cobb angle $\left({ }^{\circ}\right)$ & $4.08 \pm 1.10$ & $3.98 \pm 1.44$ & 0.685 \\
\hline $\begin{array}{l}\text { Restoration rate of vertebral } \\
\text { height (\%) }\end{array}$ & $45.79 \pm 9.46$ & $30.23 \pm 16.43$ & $<0.001$ \\
\hline Cement leakage & $2(3.2 \%)$ & 5 (7.9\%) & 0.243 \\
\hline Adjacent vertebral fracture & I (I.6\%) & $3(4.8 \%)$ & 0.310 \\
\hline
\end{tabular}

Abbreviations: ODI, Oswestry Disability Index; VAS, visual analog score; VO, vertebral osteotome. 
of PVP in our study. The mechanism behind the restoration of vertebral height during vertebroplasty is probably due to two factors. First, it is a well-known phenomenon in orthopedic literature to experience improvement of fracture height simply by placing the patient prone. Second, the pressure and volume of PMMA cement injected help to preserve positional changes and might restore fracture height. ${ }^{16}$ The patients with VO had a higher restoration rate of vertebral height than that in the control group. Because the curved tip of VO could reach the inner of vertebral body, bone cement could be injected into the cracks and cavities where the VO could reach. In the traditional method, if we wanted to inject the bone cement into the inner cracks of vertebral body, the only way was improving the injection pressure, which contributed to a more consumption of cement volume, even a new crack in vertebral body or the damage to the posterior wall of the vertebral body, especially in old patients with osteoporosis. Too much cement volume will lead to too much recovery of vertebral height that may increase the tension around vertebral soft tissues and lead to improvement of stress in augmented vertebrae and their adjacent sections, and instability among vertebrae. ${ }^{17}$ Meanwhile, anterior and posterior height losses are also important signs: this may indicate spinal canal compromise and vertebral collapse in the future. ${ }^{18}$ To achieve the adequate balanced point of vertebral body, VO could solve this problem.

Several studies had showed that no association was found between the injected cement volume and pain relief. ${ }^{19,20}$ On the contrary, it was associated with an increased risk of complications. A clinical study on the relationship between the volumetric analysis of cement in vertebroplasty with clinical outcome and complications showed that a volume larger than $11.65 \%$ led to a significantly increased incidence of leakage and adjacent fractures. ${ }^{21}$ An in vivo study following PVP showed that for restoration of vertebral body strength and stiffness, vertebral body cement filling degrees of $16 \%$ and $30 \%$ were required, respectively. ${ }^{22}$ Interestingly, although VO creates a cavity in the vertebral body, cement volume is less by the use of our new instrument. The only explanation is the less injection pressure used by VO. To achieve a better surgical effect, a uniform diffusion of bone cement in vertebral body is required. ${ }^{23}$ In the traditional method, cannula is fixed in the vertebral body. Diffusion of bone cement can be controlled by the injection pressure. VO has already reduced the resistance of vertebral body to bone cement. Although, no essays have demonstrated that high injection pressure would contribute to more volume of bone cement. In our study, the volume of bone cement in the VO group was less than that in the control group. The cavity made by VO does not mean more consumption of bone cement. On the contrary, traditional method with high injection pressure makes itself a cost of bone cement. Since minimal required cement volume for both pain relief and restoration of mechanical properties is recommended. It indicates that VO is a safe device.

Except for cement volume, cement distribution is also an important indicator of operative complications and postoperative recovery. Zhang et al found that patients with bone cement distributed around both the upper and lower endplates had the lowest rate of experiencing recompression compared to other patterns of bone cement distribution. ${ }^{24}$ Previous studies showed that a larger bone-cement interface would achieve a relatively higher vertebral strength and reduce leakage rate. ${ }^{25}$ It was suggested that the cement should spread through the vertebral body in a controlled manner that appeared fluoroscopically as a "uniformly expanding cloud"26. Insufficient cement distribution in the fractured area might lead to unrelieved pain after PVP. An asymmetrical cement distribution around fractured area was more likely to induce recollapse of augmented vertebrae because they increased maximum von Mises stress in the cancellous bone and cortical bone significantly. ${ }^{27}$ In the present study, we used the mean ratio of bright areas to the whole vertebra area both in the AP and lateral views under X-rays as the measurement of cement distribution. It showed that when the cement volume is constant, the more extensive the cement distribution is, the better the surgery outcomes are. ${ }^{28}$ The same indexes were used in this study. The cement distribution in the VO group was larger than that in the control group. Although the relationship between the cement distribution and pain relief was not explored, the lower VAS and ODI demonstrated the better recovery by $\mathrm{VO}$ method.

The end of VO had the ability of creating large curvature so that it could not destroy posterior vertebral wall even with much force. To reduce the leakage during PVP, injected cement should be kept away from posterior vertebral wall. Depression of the thoracolumbar posterior vertebral wall might be informative for the estimation of cement location on C-arm images. ${ }^{29}$ Our new device VO with side-opening cannula is operated in the unilateral approach. The cannula ensures the directional transport of bone cement and reduces its impact force to the posterior vertebral wall. There is no significant difference in cement leakage between the VO group and the traditional method group, which indicates that VO will not increase the risk of cement leakage. 


\section{Limitations}

The main limitations of our study are relatively small sample size and short follow-up period. However, we performed PSM method to compensate for the size shortcoming. It is still meaningful in finding the characteristics and advantages of VO.

\section{Conclusion}

The VO device with side-opening bone filler device makes PVP safe and effective, with less cement consumption. Although it lasts longer, the restoration rate of vertebral height and cement distribution can be improved, which contributes to a better pain relief.

\section{Ethics approval}

All procedures performed in studies involving human participants were in accordance with the ethical standards of the institutional research committee and with the 1964 Declaration of Helsinki and its later amendments or comparable ethical standards.

\section{Disclosure}

The authors report no conflicts of interest in this work.

\section{References}

1. Han SL, Wan SL, Li QT, et al. Is vertebroplasty a risk factor for subsequent vertebral fracture, meta-analysis of published evidence? Osteoporos Int. 2015;26(1):113-122.

2. Savage JW, Schroeder GD, Anderson PA. Vertebroplasty and kyphoplasty for the treatment of osteoporotic vertebral compression fractures. J Am Acad Orthop Surg. 2014;22(10):653-664.

3. Esses SI, Mcguire R, Jenkins J, et al. The treatment of symptomatic osteoporotic spinal compression fractures. JAm Acad Orthop Surg. 2011;19(3): $176-182$.

4. Huang H, He S, Fang W, et al. Percutaneous vertebroplasty for treatment of painful osteoporotic vertebral compression fractures: a retrospective analysis of clinical efficacy. Zhonghua Yi Xue Za Zhi. 2014;94(27):2119-2222.

5. Sebaaly A, Nabhane L, Issa El Khoury F, Kreichati G, El Rachkidi R. Vertebral augmentation: state of the art. Asian Spine J. 2016;10(2): 370-376.

6. Liu J, Li X, Tang D, et al. Comparing pain reduction following vertebroplasty and conservative treatment for osteoporotic vertebral compression fractures: a meta-analysis of randomized controlled trials. Pain Physician. 2013;16(5):455-464.

7. Chen C, Bian J, Zhang W, Zhang W, Zhao C, Wei H. Unilateral versus bilateral vertebroplasty for severe osteoporotic vertebral compression fractures. J Spinal Disord Tech. 2014;27(8):E301-E304.

8. Guo Z, Xq L. The effect comparison of the percutaneous vertebroplasty for osteoporotic vertebral compression fractures via the unilateral and bilateral transpedicular approach. Chin J Mod Oper Surg. 2015;19:439-442.

9. Zhang L, Liu Z, Wang J, et al. Unipedicular versus bipedicular percutaneous vertebroplasty for osteoporotic vertebral compression fractures: a prospective randomized study. BMC Musculoskelet Disord. 2015; $16: 145$.
10. Yan L, Jiang R, He B, Liu T, Hao D. A comparison between unilateral transverse process-pedicle and bilateral puncture techniques in percutaneous kyphoplasty. Spine. 2014;39(26 Spec No.):B19-B26.

11. van Meirhaeghe J, Bastian L, Boonen S, et al. A randomized trial of balloon kyphoplasty and nonsurgical management for treating acute vertebral compression fractures: vertebral body kyphosis correction and surgical parameters. Spine. 2013;38(12):971-983.

12. Heran MK, Legiehn GM, Munk PL. Current concepts and techniques in percutaneous vertebroplasty. Orthop Clin North Am. 2006;37(3):409-434.

13. Zhang LG, Gu X, Zhang HL, et al. Unilateral or bilateral percutaneous vertebroplasty for acute osteoporotic vertebral fracture: a prospective study. J Spinal Disord Tech. 2015;28(2):E85-E88.

14. Chen B, LiY, Xie D, Yang X, Zheng Z. Comparison of unipedicular and bipedicular kyphoplasty on the stiffness and biomechanical balance of compression fractured vertebrae. Eur Spine J. 2011;20(8):1272-1280.

15. Lunt M, O’Neill TW, Felsenberg D, et al. Characteristics of a prevalent vertebral deformity predict subsequent vertebral fracture: results from the European Prospective Osteoporosis Study (EPOS). Bone. 2003;33(4):505-513.

16. Teng MM, Wei CJ, Wei LC, et al. Kyphosis correction and height restoration effects of percutaneous vertebroplasty. AJNR Am J Neuroradiol. 2003;24(9):1893-1900.

17. Kim YJ, Lee JW, Kim KJ, et al. Percutaneous vertebroplasty for intravertebral cleft: analysis of therapeutic effects and outcome predictors. Skeletal Radiol. 2010;39(8):757-766.

18. Seo JY, Kwon YS, Kim KJ, Shin JY, Kim YH, Ha KY. Clinical importance of posterior vertebral height loss on plain radiography when conservatively treating osteoporotic vertebral fractures. Injury. 2017;48(7):1503-1509.

19. Jacobson RE, Granville M, Hatgis J, Berti A. Low volume vertebral augmentation with Cortoss $₫$ cement for treatment of high degree vertebral compression fractures and vertebra plana. Cureus. 2017;9(2):e1058.

20. Liebschner MA, Rosenberg WS, Keaveny TM. Effects of bone cement volume and distribution on vertebral stiffness after vertebroplasty. Spine. 2001;26(14):1547-1554.

21. Jin YJ, Yoon SH, Park KW, et al. The volumetric analysis of cement in vertebroplasty: relationship with clinical outcome and complications. Spine. 2011;36(12):E761-E772.

22. Molloy S, Mathis JM, Belkoff SM. The effect of vertebral body percentage fill on mechanical behavior during percutaneous vertebroplasty. Spine. 2003;28(14):1549-1554.

23. Dong JK, Tae WK, Kwan HP, et al. The proper volume and distribution of cement augmentation on percutaneous vertebroplasty. J Korean Neurosurg. 2010;48:125-128.

24. Zhang L, Wang Q, Wang L, Shen J, Zhang Q, Sun C. Bone cement distribution in the vertebral body affects chances of recompression after percutaneous vertebroplasty treatment in elderly patients with osteoporotic vertebral compression fractures. Clin Interv Aging. 2017;12:431-436.

25. Tan QC, Wu JW, Peng F, et al. Augmented PMMA distribution: improvement of mechanical property and reduction of leakage rate of a fenestrated pedicle screw with diameter-tapered perforations. J Neurosurg Spine. 2016;24(6):971-977.

26. Baroud G, Crookshank M, Bohner M. High-viscosity cement significantly enhances uniformity of cement filling in vertebroplasty: an experimental model and study on cement leakage. Spine. 2006;31(22):2562-2568.

27. Liang D, Ye LQ, Jiang XB, et al. Biomechanical effects of cement distribution in the fractured area on osteoporotic vertebral compression fractures: a three-dimensional finite element analysis. J Surg Res. 2015;195(1):246-256.

28. He X, Li H, Meng Y, et al. Percutaneous kyphoplasty evaluated by cement volume and distribution: an analysis of clinical data. Pain Physician. 2016;19(7):495-506.

29. Lin BJ, Li CC, Ma HI, Cc L, Hi M. Intradural cement leakage after percutaneous vertebroplasty. Turk Neurosurg. 2015;25(6):940-942. 
The Journal of Pain Research is an international, peer reviewed, open access, online journal that welcomes laboratory and clinical findings in the fields of pain research and the prevention and management of pain. Original research, reviews, symposium reports, hypothesis formation and commentaries are all considered for publication
The manuscript management system is completely online and includes a very quick and fair peer-review system, which is all easy to use. Visit http://www.dovepress.com/testimonials.php to read real quotes from published authors. 